\title{
nature
}

\section{Restoring faith in anthropology}

Rebuttals of a controversial book that alleges malpractice by distinguished anthropologists have so far confused rather than clarified the situation. An independent inquiry is urgently needed.

A merican anthropologists are going through a traumatic episode that calls for decisive and definitive action. Journalist Patrick Tierney has written a book - Darkness in El Dorado: How Scientists and Journalists Devastated the Amazon - that alleges scientific misconduct by high-profile members of the anthropological community. The allegations include experimentation without consent on Yanomami Indians in Venezuela, the possible spreading of measles, fever and other diseases by researchers, and various abuses of indigenous peoples, including a French anthropologist's use of Yanomami boys for sex.

At its annual meeting last month in San Francisco, the executive board of the American Anthropological Association (AAA) announced that a panel would be set up to determine whether there should be a full investigation into the allegations in Tierney's book (see Nature 408, 391;2000). The seven-member panel was chosen last week. It will deliver its recommendations to the AAA's executive board in February, and the board will then decide whether - and how - to examine allegations about anthropological practices that took place in isolated jungles more than 30 years ago.

But the breadth of the allegations, the difficulty and cost of conducting an international investigation, and the need for a variety of expert perspectives, require a more comprehensive probe if it is to satisfy both US and Venezuelan scientists. Louise Lamphere of the University of New Mexico, the president of the AAA, has already asked the American Association for the Advancement of Science (AAAS) to consider examining the allegations regarding the medical and genetic issues, as these are outside the AAA's normal purview. The AAAS board considered this last week, but has yet to announce its decision.

Given the enormity of the job, the high stakes for anthropology and the personal reputations of those attacked by Tierney, it is imperative that a complete investigation is carried out by an independent agency or commission - possibly with government funding. Such an untainted probe could overcome the partisan politics now playing out in the anthropology community. The difficulty is in identifying an agency with expertise and without bias. There may even be some outside the scientific community who will question whether the AAAS has the necessary independence.

\section{The charges}

Tierney's book focuses on the behaviour of anthropologist Napoleon Chagnon and deceased geneticist James Neel, beginning in the late 1960 s in isolated villages in Venezuela and continuing into the 1990s. Among other charges, they are accused of collecting blood from the Yanomami for the US Atomic Energy Commission without the natives' consent, and of possibly causing native deaths from using a measles vaccine. Tierney also describes how blood was acquired from the Yanomami with payment in steel machetes or axes. He charges that this was highly damaging to the people's indigenous culture.

The activities alleged by Tierney occurred when Neel and Chagnon were at the University of Michigan, where Neel had started one of the nation's first genetics departments. Chagnon later moved to the University of California at Santa Barbara (UCSB), from which he retired about a year ago. In statements posted on a UCSB website (http://www.anth.ucsb.edu), Chagnon has denied any impropriety.

Early in September, when the book's allegations started spreading in e-mails, supporters of the two researchers jumped into high gear, sending out a barrage of material highly critical of the book. This prompted a series of missteps that have clouded a fair assessment of the book's charges.

For example, invoking guidelines for charges of scientific misconduct, the University of Michigan set up an inquiry panel to examine the charges. On 27 September, the university issued a statement criticizing the book and disputing its central allegations. But Michigan officials did this without ever seeing the book or examining the substantial documentation obtained by Tierney on which the book was based. Later, after receiving an uncorrected proof of the book, Michigan issued an updated document, which itself remains controversial.

\section{Academy statement}

Michigan officials also contacted the National Academy of Sciences, which put out a critical statement in early November. This statement (see http://nationalacademies.org) has since been challenged by Tierney. Meanwhile, UCSB administrators have undertaken no formal inquiry. An anthropology professor at UCSB has issued a long, critical document. But this document does not represent the official view of the university, although Chagnon's supporters have stated that it does.

These miscues - which brought groans from the AAA leadership, as it has made its job more difficult — have prompted so much confusion that an independent investigation is imperative.

But the most important need is to restore faith - not only in anthropology but also in medicine - that may have been lost as a result of the book's allegations. Conducting research today in the natural environments of emerging nations is a delicate matter. The rights of host governments, indigenous peoples and various other interests must all be considered, in a political climate starkly different from when the Neel/Chagnon team first trekked into the forest. Furthermore, because Tierney has questioned whether an appropriate measles vaccine was used on the Yanomami in 1968, there are fears that it will now be harder to vaccinate or treat indigenous peoples.

To its credit, the AAA has acknowledged that the book identifies weaknesses in anthropological research techniques. And last month it decided to examine how its research guidelines could be refined to better protect human subjects and their cultures.

Time is of the essence for this process. Already, other scientists including botanists and ecologists - fear that the offences alleged by Tierney will harm their research efforts in developing nations. If the allegations in Tierney's book aren't appropriately addressed, a range of scientific explorations could be damaged. Tierney's book has been called "anti-science" by some of its critics. Although the investigations have yet to be conducted, there are some signs that Tierney's charges cannot be lightly dismissed. It would certainly be "anti-science" to botch an assessment of the legitimacy of his accusations. 